Review

\title{
Biocompatibility of Bacterial Cellulose Based Biomaterials
}

\section{Fernando G. Torres ${ }^{1, *}$, Solene Commeaux ${ }^{1,2}$ and Omar P. Troncoso ${ }^{1}$}

1 Polymers and Composites Group, Catholic University of Peru (PUCP), Lima 32, Peru; E-Mail: troncoso.op@pucp.pe

2 Polytech Montpellier, University of Montpellier, Montpellier 34095, France; E-Mail: solene.commeaux@polytech.univ-montp2.fr

* Author to whom correspondence should be addressed; E-Mail: fgtorres@pucp.edu.pe; Tel./Fax: +511-626-2000.

Received: 26 July 2012; in revised form: 12 October 2012 / Accepted: 22 October 2012 / Published: 5 December 2012

\begin{abstract}
Some bacteria can synthesize cellulose when they are cultivated under adequate conditions. These bacteria produce a mat of cellulose on the top of the culture medium, which is formed by a three-dimensional coherent network of pure cellulose nanofibers. Bacterial cellulose (BC) has been widely used in different fields, such as the paper industry, electronics and tissue engineering due to its remarkable mechanical properties, conformability and porosity. Nanocomposites based on BC have received much attention, because of the possibility of combining the good properties of $\mathrm{BC}$ with other materials for specific applications. $\mathrm{BC}$ nanocomposites can be processed either in a static or an agitated medium. The fabrication of $\mathrm{BC}$ nanocomposites in static media can be carried out while keeping the original mat structure obtained after the synthesis to form the final nanocomposite or by altering the culture media with other components. The present article reviews the issue of biocompatibility of $\mathrm{BC}$ and $\mathrm{BC}$ nanocomposites. Biomedical aspects, such as surface modification for improving cell adhesion, in vitro and in vivo studies are given along with details concerning the physics of network formation and the changes that occur in the cellulose networks due to the presence of a second phase. The relevance of biocompatibility studies for the development of BC-based materials in bone, skin and cardiovascular tissue engineering is also discussed.
\end{abstract}

Keywords: bacterial cellulose; biocompatibility; biomedical application; biomaterials 


\section{Introduction}

Cellulose is the most abundant biomass material on earth [1]. It forms the basic structural matrix for plant cell walls. It is mainly used in the textile and paper industry, and it is obtained from vegetal products.

Bacterial cellulose (BC) is a type of cellulose synthesized by some bacteria. In stationary culture conditions, these bacteria produce a thick gel or pellicle of cellulose on the surface of the liquid medium. BC differs from plant cellulose in its higher purity, crystallinity, degree of polymerization and tensile strength [2-5]. BC has $\mathrm{I} \alpha$ and I $\beta$ crystalline forms, unlike the cellulose of plants that present mainly the I $\beta$ structure [6].

Traditionally, BC is used as raw material for a Filipino dessert called "nata-de-coco" [7], and it is also present in the mat used for the preparation of a beverage known as "kombucha tea" $[2,8]$. Biocompatibility of BC-based products have made them suitable for several biomedical applications, including membranes for wound dressings [9], scaffolds for tissue engineering [10-13], substrates for cell seeding [14,15], structures for biomineralization of hydroxyapatite [16], etc.

In this paper, we review the use of $\mathrm{BC}$ and $\mathrm{BC}$-based structures as biomaterials and discuss issues related to their biocompatibility. First, we present the main characteristics of BC structures, including their morphology, their mechanical properties, as well as the processing routes used for their production. Then, we discuss the properties of $\mathrm{BC}$ as a biomaterial, including its rheological properties in the humid state, biocompatibility and biodegradability. The following section deals with the techniques used for improving the biocompatibility of BC. Some examples of surface modification and preparation of $\mathrm{BC}$ composites are given. Finally, we give several examples of BC-based structures for biomedical and clinical applications, with details concerning the biocompatibility achieved in each case.

\section{Bacterial Cellulose Properties}

BC structures are formed by extracellulary-excreted nanofibers produced by various species of bacteria, including Acetobacter, Rhizobium, Agrobacterium and Sarcina [17]. These nanofibers are about $100 \mathrm{~nm}$ in diameter and form a coherent 3D network. Macroscopically, the BC network is constructed as a pellicle that acquires the shape of the recipient where the bacteria is grown [18].

The nanofibers of $\mathrm{BC}$ are ribbon-like structures of around $100 \mathrm{~nm}$ in diameter and around $100 \mu \mathrm{m}$ in length. These ribbons are made up of bundles of cellulose microfibrils of $2-4 \mathrm{~nm}$ in diameter $[2,3,19,20]$. In its native state, $\mathrm{BC}$ is a water-swollen network of cellulose nanofiber (Figure 1). Figure 1 shows a SEM image of a native BC network. Grande et al. [10] have used image analysis to measure the morphological properties of dried BC networks. The average mesh size (distance between junction points) is $0.523 \pm 0.273 \mu \mathrm{m}$, while the orientation (the average angle formed by the segments and the $\mathrm{x}$-axis) of the nanofibers is $85.64 \pm 0.56^{\circ}$.

The mechanical properties of these structures strongly depend on the properties of the network. Grande et al. [10] have reported mechanical properties of hot-pressed BC sheets. They have found an average Ultimate Tensile Strength (UTS) value of $241.42 \pm 21.86 \mathrm{MPa}$, a maximum elongation of $8.21 \pm 3.01 \%$ and a Young's modulus of $6.86 \pm 0.32 \mathrm{GPa}$. The elastic modulus of an individual BC nanofiber has been measured by means of Atomic Force Microscopy (AFM). Guhados et al. [21] have measured a value of $78 \pm 17 \mathrm{GPa}$ for Young's modulus of bacterial cellulose nanofibers with diameters ranging from $35 \mathrm{~nm}$ to $90 \mathrm{~nm}$. 
Figure 1. SEM micrograph of a bacterial cellulose sample showing a coherent 3-D network formed by cellulose fibers connected by physical joints [22].

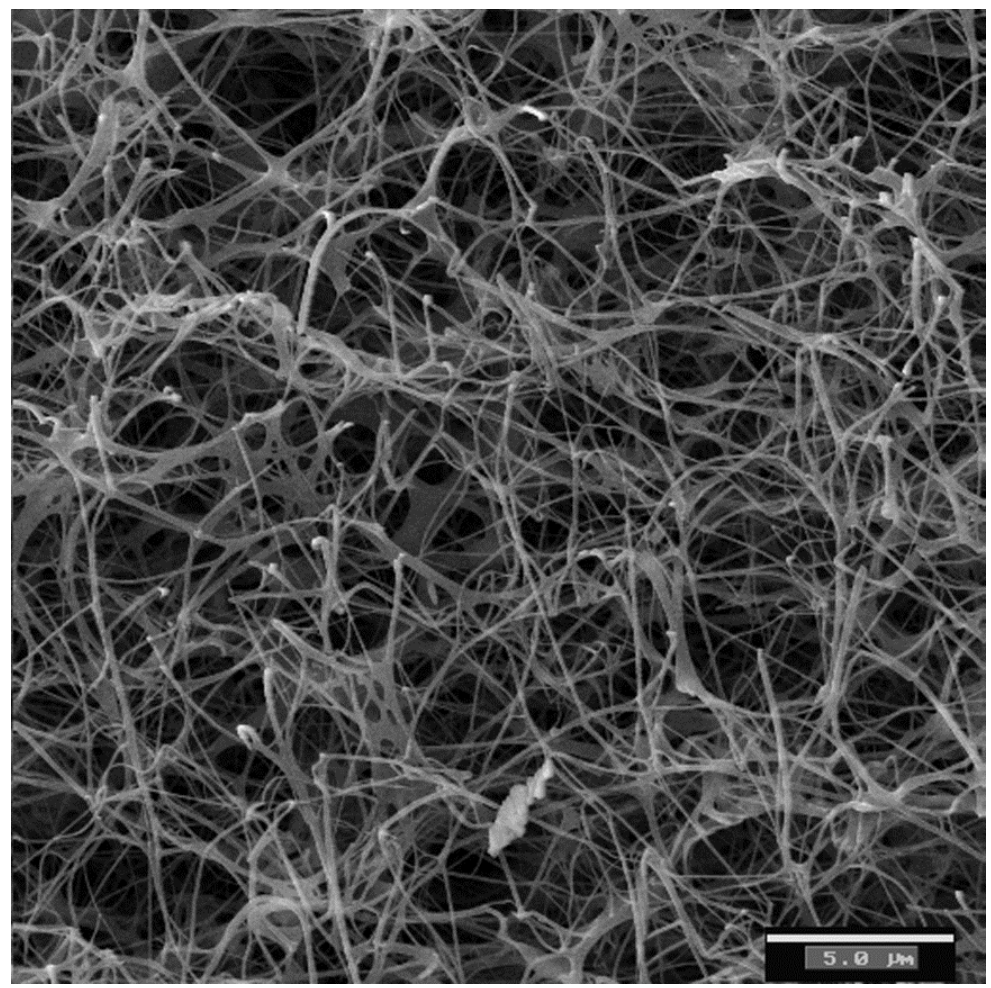

These remarkable mechanical properties are due to the uniform ultrafine-fiber network structure, the high planar orientation of the ribbon-like fibers when compressed into sheets and the good chemical stability of $\mathrm{BC}$ [23]. Applications include strong paper, headphone diaphragms, electro-acoustic transducers, high strength paper, components for precision optical devices, etc. [24,25].

$\mathrm{BC}$ networks can be used in its native state as a gel-like material, hot-pressed as a dry sheet or freeze-dried. They can also be used as part of a composite with another material. There are several reported processing routes for the production of $\mathrm{BC}$ composites. Some authors have tried to disintegrate the cellulose network structure in order to blend it as standard nanofiller [2,3,20,25].

Other routes consist in introducing a second phase during the development of the BC network. Touzel et al. [26] produced a double network gel of BC-pectin by adding pectin to the culture medium. Mormino et al. [27] have incorporated solid reinforcing particles in the forming BC gel by means of a rotating disc bioreactor.

Grande et al. [23] have reported the introduction of starch in the BC network by modifying the BC culture media. This "bottom-up" route is depicted in Figure 2. Starch granules are added to the culture medium before bacteria are inoculated. Then, the starch-medium suspension is autoclaved at $121^{\circ}$. During this process, the starch phase undergoes a "first gelatinization". The starch granules swell, leach amylose and lose their crystalline structure. When the starch-medium suspension cools down, bacteria are inoculated, and the nanofibers network is formed in the presence of a partially gelatinized starch structure. Finally, the BC-starch gels are hot-pressed, and the starch phase undergoes a "second gelatinization". 
Figure 2. Scheme of the BC-starch Bottom-Up process: (a) Starch granules are in suspension in the culture medium; (b) After autoclaving, starch is partially gelatinized, amylose leaches and granules swell; (c) BC nanofibrils grow in presence of the partially gelatinized starch; (d) After hot-pressing, the nanocomposite shows interpenetrating networks of amylose and cellulose [23].

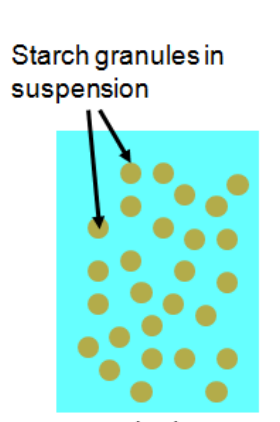

(a)

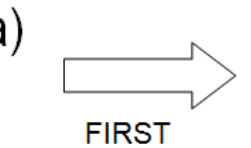

GELATINIZATION

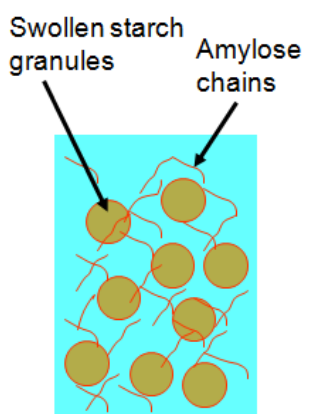

(b)

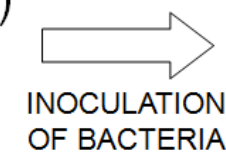

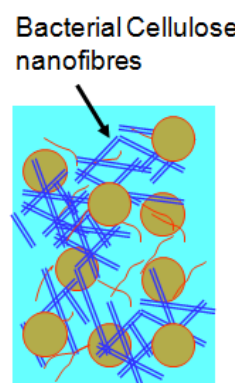

(c)

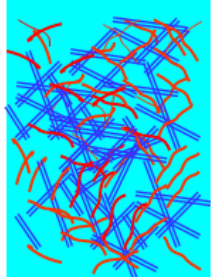

(d)

\section{Bacterial Cellulose as a Biomaterial}

$\mathrm{BC}$ is used in the humid state for most biomedical applications. In this state, the $\mathrm{BC}$ network resembles a gel. $\mathrm{BC}$ gels are not easily rehydrated once they have lost water. Due to their irreversible nature, native BC gels have been named "never-dried BC" [28]. The mechanical properties of BC gels resemble the properties of soft tissues [29]. The reported stress at break is $2 \mathrm{MPa}$, with 99\% water content.

Torres et al. [22] have measured the rheological properties of BC gels. They have found that both the storage modulus (G') and the loss modulus ( $\mathrm{G}^{\prime}$ ') remain almost constant in the range of $10-100{ }^{\circ} \mathrm{C}$. They have also found that the storage modulus of BC gels decreases as the applied stress increases, which is a typical behavior of physical gels due to the permanent alteration or even disruption of cross-links [30]. In addition, BC displays a "Reversible Stress Softening" type of behavior, in which the reduction of storage modulus is reversible. This "Reversible Stress Softening" has also been found in other biological gels, such as actin gels [31], and it is considered to be a protection mechanism.

According to Gatenholm and Klem [32], the use of BC gels for the fabrication of biomedical products has advantages over the use of other types of cellulose and polymers. These advantages include the fact that the 3D shape and the fiber network architecture can be controlled. Moreover, composite formation can be achieved in the culture medium, and the possibility of coating BC gels with foreign surfaces improves their biocompatibility.

Biocompatibility is the ability of a material to perform with an appropriate host response in a specific application [33]. Biocompatibility does not only refer to the quality of not having toxic effects on biological systems, but also to the need of having an appropriate host response to ensure satisfactory performance on a specific application. Petersen and Gatenholm [27] have pointed out that biocompatibility of $\mathrm{BC}$ for tissue engineering applications can be related to the fact that its structure shows similarities with extracellular matrix components, such as collagen. In fact, collagen and BC 
nanofibers have similar diameters (around $100 \mathrm{~nm}$ ) and are extracellularly assembled from precursor molecules into polymer chains.

Mendes et al. [14] have assessed the tissue reaction in the presence of a BC membrane after subcutaneous implantation in mice. They performed analysis of histological sections of the BC membrane and the surrounding tissue at 7, 15, 30, 60 and 90 days post-surgery. They found no evidence of foreign body reaction throughout the study period. Polymorphonuclear cells and lymphocytes observed at 7, 15 and 30 days post-surgery suggest a mild inflammatory response. By contrast, at 60 and 90 days post-surgery, no inflammatory infiltrate was observed. Helenius et al. [15] implanted pieces of $\mathrm{BC}$ on rats. They also found no histologic signs of inflammation and no presence of giant cells. The formation of new blood vessels around and inside the implanted cellulose was observed. In vivo tests of tubular shaped BC membranes for the replacements of blood vessels have shown similar results. No macroscopic or microscopic signs of inflammation around the implants were found. Instead, it was found that fibroblasts had actually infiltrated BC [18,34].

Due to its biocompatibility, BC has been used as a scaffold for tissue engineering application $[15,28]$. Hutmacher [35] has identified several requirements that tissue engineering scaffolds should fulfill. Scaffolds should have interconnecting pores of appropriate scale to favor tissue integration and vascularization, appropriate surface chemistry to favor cellular attachment, differentiation and proliferation, adequate mechanical properties and should be made from materials with controlled biodegradability or bioresorbability so that tissue will eventually replace the scaffold.

Of all the requirements listed by Hutmacher, biodegradability seems to be the most difficult to meet for BC-based biomaterials. Cellulose has a high degree of crystallinity and a compact structure. Cellulase enzymes capable of performing cellulose hydrolysis are not present in animals, but are produced by fungi and bacteria. Li et al. [11] have reported the enhancement of the biodegradation of $\mathrm{BC}$ in vitro (in water, phosphate-buffered saline and simulated body fluid) through periodate oxidation. This chemical treatment kept the original network structure of $\mathrm{BC}$ intact and made it possible to prepare a BC-based scaffold that could degrade in water, phosphate buffered saline (PBS) and the simulated body fluid (SBF).

\section{Improvement of Biocompatibility of BC Structures}

BC and BC-based composites have been used as scaffolds for cell seeding. Several studies have confirmed that different cells, such as human embryonic kidney cells (HEK) [12], bone forming osteoblasts (OB) [13], fibroblasts [13], chondrocytes [36], human smooth muscle cells (SMC) [28], etc., can grow in the presence of BC. Figure 3 shows HEK cells growth on a BC based composite. However, cell adhesion cannot be achieved with native $\mathrm{BC}$ structures.

It seems that the surface of native $\mathrm{BC}$ does not promote cell adhesion. The interfacial characteristics of biomaterials play a key role in cell adhesion. The surfaces should promote the specific absorption of proteins and subsequent cellular interaction [37]. Several studies have been carried out with the aim of modifying BC surface to optimize the BC-cells interactions. These modifications change the physical properties of $\mathrm{BC}$ structures, such as wettability, porosity and surface chemistry. It has been shown that improvement of cell adhesion may be achieved by the immobilization of adhesion proteins onto the 
biomaterial surface [38]. However, the results show that these treatments have different results, according to the specific cells used.

Figure 3. Optical micrographs of HEK cells for one day of culture in a composite of BC-Hidroxyapatite [12].

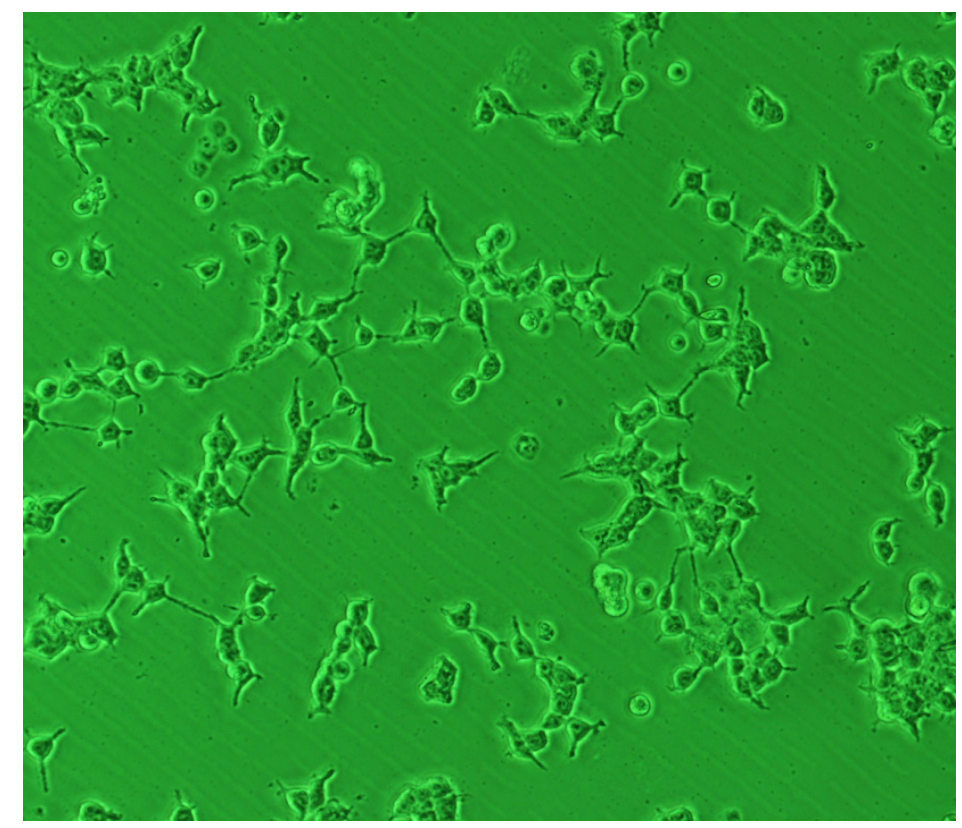

Experimental evidence shows that surface modification of $\mathrm{BC}$ by nitrogen-containing plasma improves cell adhesion in the case of microvascular and neuroblast cells, but has no effect on fibroblast cells [39]. Pertile et al. [38] have used some of the small signaling peptides found in the proteins of the extra-cellular matrix, such as the integrin-ligand sequences isoleucine-lysine-valine-alanine-valine (IKVAV) fused to a carbohydrate-binding module (CBM3), in order to modify the surface of native $\mathrm{BC}$ with the aim of improving cell adhesion. These recombinant proteins were adsorbed to BC structures and were able to improve the adhesion of neuronal and mesenchymal cells, but had no effect on the other cell lines tested. Andrade et al. [40] have improved the adhesion of fibroblasts to BC. They managed to coat BC nanofibers with cellulose-binding module (CBM) fused to Arg-Gly-Asp (RGD). The results showed that fibroblasts exhibit improved ability to interact with BC sheets coated with CBM-RGD.

A different approach to improve $\mathrm{BC}$ biocompatibility consists in preparing $\mathrm{BC}$ composites with various biomaterials. Wang et al. [41] have reported the synthesis of a cellulose/gelatine composite via crosslinking by procyanidin. The results showed that the proliferation, infiltration and adhesion of fibroblasts are improved with regard to native BC. Indeed, gelatine, a polypeptide derived from an extracellular matrix, and a denatured form of collagen, exhibits many properties such as good biocompatibility, low immunogenicity, adhesiveness, promotion of cell adhesion and growth and low cost. Hence, it can be used as an alternative material to collagen in tissue engineering.

Collagen has also been used to improve $\mathrm{BC}$ biocompatibility. Collagen has been used in biomedical applications due to its biodegradability, low antigenicity and cell-binding properties [27]. By contrast, collagen has low mechanical properties, possible inter-infection and high price, thus limiting its use in biomedical fields [42]. Cai et al. [43] prepared BC-collagen composites by immersing a BC membrane 
in collagen solution. The incubated fibroblast cells performed well with regard to cell adhesion and proliferation. The BC-collagen composites prepared showed much better cytocompatibility than pure native $\mathrm{BC}$.

$\mathrm{BC}$-chitosan composites have been prepared in order to improve some of the properties of native BC structures. Kim et al. [44] have prepared BC-Chitosan composites by immersing wet BC pellicles in a chitosan solution followed by a freeze-drying process. The morphological analysis performed suggested that chitosan molecules can penetrate into $\mathrm{BC}$ forming a three-dimensional multilayer structure scaffold. The biocompatibility of such BC-Chitosan composites was evaluated by cell adhesion studies. Cell adhesion and proliferation was achieved. In general, the BC-chitosan composites showed much better biocompatibility with regard to pure $\mathrm{BC}$.

Also, chitosan has been shown to improve some other important characteristics of BC. Ul-Islam et al. [45] prepared BC-Chitosan composites that showed improved water holding capacity (WHC) and water release rate (WRR). Cai et al. [46] reported the increase of thermal stability of BC-Chitosan composites with regard to native BC structures. They have found that the thermal degradation temperature increases from $263{ }^{\circ} \mathrm{C}$ to $366{ }^{\circ} \mathrm{C}$, with the chitosan content increasing from $1.2 \%$ to $45 \%$. By contrast, the tensile strength and Young's modulus of BC-Chitosan composites tend to decrease with the increase in chitosan content, and the crystallinity tends to decrease from $82 \%$ (pure BC) to $61 \%$ (BC-Chitosan composites) [44].

Other biomaterials used to improve the biocompatibility of BC include starch [22,47], hydroxyapatite [12,16,48-52], poly(vinyl alcohol) [53-55], poly(methyl methacrylate) [56] and polyacrylamide [57].

Biocompatibility can also be improved by controlling the properties of BC-based structures. The porosity of $\mathrm{BC}$ networks can influence the response of cells. The density of the mesh of the $\mathrm{BC}$ networks could prevent cell migration into the biomaterial [27]. Porogens have been used to increase the porosity of BC networks. Backdahl et al. [58] used starch and paraffin wax as porogens. They were able to control the pore size and interconnectivity of pores in BC networks by controlling the size of the starch and paraffin wax particles used. Their tests showed that muscle cells were able to attach themselves inside the pores.

The control of porosity can also be used to modify the water holding capacity (WHC) and water release rate of $\mathrm{BC}$ structures (WRR). Both WHC and WRR determine the usefulness of $\mathrm{BC}$ as a dressing material [59]. The moisture content of a dressing material accelerates the wound healing process and protects wounds against contamination [60]. Dahman [61] claims that in the case of BC, its loose fibril arrangement, high surface area per unit mass and hydrophilic nature results in a very high WHC (100-200 times its dry weight). Rambo et al. [62] have reported the modification of porosity of $\mathrm{BC}$ networks by using a template with pins of different diameters (60-300 um).

\section{BC Based Structures for Biomedical Applications}

\subsection{Bone Tissue Engineering and Bone Grafting}

Bone is a composite material with an organic phase (collagen and noncollagenous proteins) and an inorganic mineral phase (calcium hydroxyapatite). Among the different materials used in bone tissue engineering and bone grafts, ceramics have been used extensively [63] due to their osteoconductivity. 
BC can be a good matrix for obtaining different types of calcium carbonate crystals with improved biocompatibility. Stoica-Guzun et al. [64] have used calcium chloride $\left(\mathrm{CaCl}_{2}\right)$ and sodium carbonate $\left(\mathrm{Na}_{2} \mathrm{CO}_{3}\right)$ as starting reactants to promote calcium carbonate deposition on bacterial cellulose membranes.

It has been proven that $\mathrm{BC}$ nanofibers can mimic collagen nanofibers for $\mathrm{Ca}-\mathrm{P}$ minerals deposition via biomineralization. The resultant $\mathrm{Ca}-\mathrm{P}$ minerals are platelet-like calcium-deficient hydroxyapatite (Hap), similar to the hydroxyapatite found in natural bone [65]. Other authors [48,51] have induced a negative charge on $\mathrm{BC}$ by the adsorption of polyvinylpyrrolidone (PVP) to initiate the nucleation of Hap via dynamic simulated body fluid (SBF) treatment. Shi et al. [16] introduced an alkaline treatment before the biomimetic mineralization process in order to improve the mineralization efficiency. Zhang et al. [66] have used a phosphorylation reaction to introduce phosphate groups to the hydroxyl groups of $\mathrm{BC}$ and promote the growth of calcium phosphate. Wan et al. [51] have also shown that phosphorylation effectively triggers Hap formation on BC. BC-Hap composites with a third phase can also be produced.

In order to improve the biocompatibility and osteoconductivity of $\mathrm{BC}$ in bone-related biomedical applications, Grande et al. [12] have produced BC-hydroxyapatite nanocomposites (Figure 3) by adding hydroxyapatite and carboxymethylcellulose (CMC) to the culture medium. As CMC can change the viscosity of media, it was used to retard the settlement of Hap particles in the BC culture medium.

\subsection{Cardiovascular Clinical Applications}

Synthetic blood vessels of other materials, such as Dacron ${ }^{\circledR}$ and expanded polytetrafluoroethylene are available at large diameters $(6-10 \mathrm{~mm})$. By contrast, small diameters vessels $(<6 \mathrm{~mm})$ for coronary, carotid and femoral arteries are still under investigation [67]. Several studies have shown that BC can be molded into tubular form with diameter $<6 \mathrm{~mm}[18,68,69]$. Klemm et al. [18] designed a matrix in order to produce a $\mathrm{BC}$ tube (diameter $1 \mathrm{~mm}$, length $5 \mathrm{~mm}$, wall thickness $0.7 \mathrm{~mm}$ ) with a tensile strength comparable to that of normal blood vessels $(800 \mathrm{mN})$. Brown et al. [69] have prepared small tubes of BC-fibrin composites treated with glutaraldehyde in order to crosslink the polymers and allow a better match of the mechanical properties with those of native small-diameter blood vessels.

The biocompatibility of such BC-based blood vessels has been evaluated by in vivo tests. The tubes prepared by Klemm et al. [18] were used to replace part of the carotid artery (4-6 mm) of a rat. After four weeks, the $\mathrm{BC} /$ carotid artery complex was covered with connective tissue, showing that $\mathrm{BC}$ can be used as a replacement blood vessel.

BC-based blood vessels, known as BASYC $\AA$, have been tested in five mice. The BC implants were

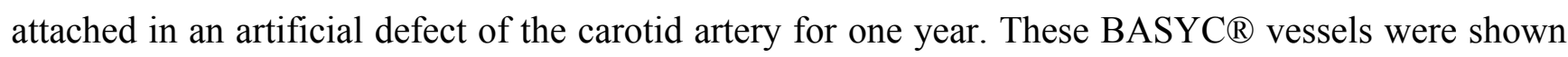
to be stable vascular conduits [34]. The tests showed that the BC-based blood vessels studied were biocompatible. Moreover, the morphological analysis carried out showed that structural modification in the contact region between the BC-based blood vessels and the surrounding media had occurred. The presence of fibroblasts in this region suggests that a process of integration without degradation (vitalization) has taken place.

The potential use of BC-based composites for the production of heart valve replacements is currently under study. Milton and Wan [55] prepared a BC-Poly(vinyl alcohol) composite that mimics the mechanical behavior of native heart valve leaflets. Their tests showed that the stress-strain 
properties for porcine aorta are matched by the one of the BC-Poly(vinyl alcohol) prepared in this study. Mohammadi [70] has also used BC-Poly(vinyl alcohol) composites for the production of heart valve leaflets. Mohammadi aimed at mimicking not only the non-linear mechanical properties displayed by porcine heart valves, but also their anisotropic behavior by applying a controlled strain to the samples, while undergoing low-temperature thermal cycling in order to induce oriented mechanical properties.

Hemocompatibility of surfaces that are in contact with blood should be further studied. It is well known that blood-contacting surfaces may activate coagulation and thrombus formation due to the interaction of such surfaces with blood proteins and platelets. Fink et al. [71] evaluated the hemocompatibility of BC-based vascular graft tubes and compared them with commercial grafts of poly(ethylene terephthalate) (PET) and expanded poly(tetrafluoroethylene)(ePTEE). They reported that BC-based grafts do not induce plasma coagulation, but induce the slowest coagulation cascade. Andrade et al. [72] have coated BC with the tripeptide Arg-Gly-Asp (RGD) to favor endothelialization and improve hemocompatibility of $\mathrm{BC}$. They cultured human microvascular endothelial cells on RGD-coated BC. The results showed that the endothelial cells formed a confluent layer, inhibiting the adhesion of platelets.

\subsection{Wound Dressings}

BC gels have been used for wound dressings. According to Czaja et al. [9], the biocompatibility of BC-based wound dressings is related to its distinctive nanofibrillar structure, which serves as an optimal wound healing environment. This nanofibrillar structure eliminates pain symptoms (by isolating the nerve endings) and enhances the absorption of wound exudates [73]. BC accelerates the process of healing of the skin in comparison with conventional wound dressings, such as wet gauze and ointments. Studies have shown that BC-based coverings reduce wound pain, accelerate re-epithelization and reduce wound infection rates and scarring $[9,68,74]$.

There are three commercially available BC-based coverings, namely Xcell®, Bioprocess ${ }^{\circledR}$ and Biofill ${ }^{\circledR}$. Legeza et al. [75] produced a $\mathrm{BC}$ wound dressing for the treatment of third degree burns that is impregnated with superoxide dismutase (an antioxidant) or poviargol (an antibiotic).

\subsection{Cartilage Replacement}

Advanced degeneration of articular cartilage is often treated with the total replacement of joints by prostheses. Due to wear and osteolysis, the lifespan of these prostheses is limited. Some studies have shown that $\mathrm{BC}$ composites could be used as cartilage replacement material. Azuma et al. [76] concluded that BC-poly(dimethyl acrylamide) double network gel has mechanical properties similar to the mechanical properties of cartilage and that may meet the requirements of artificial cartilage. However, in vivo tests that could confirm the biocompatibility of BC-based cartilage replacements have not been reported yet. BC-poly(vinyl alcohol) composites evaluated using unconfined compression testing also have elastic modulus values similar to those reported for native articular cartilage [53]. 


\subsection{Other Biomedical Applications}

Other less-documented biomedical applications include the use of $\mathrm{BC}$ for the production of contact lenses [77], electroconductive composite hydrogels biosensors [78], membranes for topical delivery of lidocaine [79] and dietary supplements for combating diabetes [80].

\section{Conclusions}

Bacterial cellulose-based structures have been used for many biomedical applications, including bone tissue engineering, blood vessels and wound dressings, among others, since BC has proved to be a nontoxic biocompatible material. Some properties of $\mathrm{BC}$, such as porosity, density, water holding capacity and its high strength make BC-based materials suitable for such biomedical applications. However, unmodified native $\mathrm{BC}$ is not always suitable for biomedical applications. For instance, cells tend to grow in the presence of native $\mathrm{BC}$, but they do not attach themselves to an unmodified native BC substrate. In order to improve BC biocompatibility, several strategies have been proposed, including surface modification, porosity modification and preparation of $\mathrm{BC}$ composites. However, the physical stability and relatively low degradation rate of cellulose inside the human body could present challenges for $\mathrm{BC}$ to be able to be used in certain biomedical applications (such as scaffolds for tissue engineering). Further studies are needed in order to elucidate the way of promoting and controlling the biodegradation of cellulose. This could in fact facilitate the use of BC-based structures in other biomedical applications.

\section{References}

1. Perez, J.; Muñoz-Dorado, J.; de la Rubia, T.; Martinez, J. Biodegradation and biological treatments of cellulos, hemicellulose and lignin: An overview. Int. Microbiol. 2002, 5, 53-63.

2. Iguchi, M.; Yamanaka, S.; Budhiono, A. Bacterial cellulose: A masterpiece of nature's arts. J. Mater. Sci. 2000, 35, 261-270.

3. Nakagaito, A.N.; Iwamoto, S.; Yano, H. Bacterial cellulose: The ultimate nano-scalar cellulose morphology for the production of high-strength composites. Appl. Phys. A Mat. Sci. Process. 2005, 80, 93-97.

4. Bae, S.; Shoda, M. Statistical optimization of culture conditions for bacterial cellulose production using Box-Behnken design. Biotechnol. Bioeng. 2005, 90, 20-28.

5. Bae, S; Sugano, Y.; Shoda, M. Improvement of bacterial cellulose production by addition of agar in a jar fermentor. J. Biosci. Bioeng. 2004, 97, 33-38.

6. Atalla, R.H.; Vanderhart, D.L. Native cellulose: A composite of two distinct crystalline forms. Scienc 1984, 223, 283-285.

7. Budhiono, A.; Rosidi, B.; Taher, H.; Iguchi, M. Kinetic aspects of bacterial cellulose formation in nata-de-coco culture system. Carbohyd. Polym. 1999, 40, 137-143.

8. Sreeramulu, G.; Zhu, Y.; Knol, W. Kombucha fermentation and its antimicrobial activity. J. Agric. Food Chem. 2000, 48, 2589-2594.

9. Czaja, W.; Krystynowicz, A.; Bielecki, S.; Brownjr, R. Microbial cellulose the natural power to heal wounds. Biomaterials 2006, 27, 145-151. 
10. Grande, C.J.; Torres, F.G.; Gomez, C.M.; Troncoso, O.P; Canet-Ferrer, J.; Martinez-Pastor, J. Morphological characterisation of bacterial Cellulose-Starch nanocomposites. Polym. Polym. Composites 2008, 16, 181-185.

11. Li, J.; Wan, Y.; Li, L.; Liang, H.; Wang, J. Preparation and characterization of 2,3-dialdehyde bacterial cellulose for potential biodegradable tissue engineering scaffolds. Mater. Sci. Eng. C 2009, 29, 1635-1642.

12. Grande, C.J.; Torres, F.G.; Gomez, C.M.; Bañó, M.C. Nanocomposites of bacterial cellulose/hydroxyapatite for biomedical applications. Acta Biomater. 2009, 5, 1605-1615.

13. Chen, Y.M.; Xi, T.; Zheng, Y.; Guo, T.; Hou, J.; Wan, Y.; Gao, C. In vitro cytotoxicity of bacterial cellulose scaffolds used for tissue-engineered bone. J. Bioact. Compat. Polym. 2009, 24, S137-S145.

14. Mendes, P.N.; Rahal, S.C.; Pereira-Junior, O.P.; Fabris, V.E.; Lenharo, S.L.; de Lima-Neto, J.F.; da Cruz Landim-Alvarenga, F. In vivo and in vitro evaluation of an acetobacter xylinum synthesized microbial cellulose membrane intended for guided tissue repair. Acta Vet. Scand. 2009, 51, 12 .

15. Helenius, G.; Bäckdahl, H.; Bodin, A.; Nannmark, U.; Gatenholm, P.; Risberg, B. In vivo biocompatibility of bacterial cellulose. J. Biomed. Mater. Res. 2006, 76, 431-438.

16. Shi, S.; Chen, S.; Zhang, X.; Shen, W.; Li, X.; Hu, W.; Wang, H. Biomimetic mineralization synthesis of calcium-deficient carbonate-containing hydroxyapatite in a three-dimensional network of bacterial cellulose. J. Chem. Technol. Biotechnol. 2009, 84, 285-290.

17. El-Saied, H.; Basta, A.H.; Gobran, R.H. Research progress in friendly environmental technology for the production of cellulose products (bacterial cellulose and its application). Polym.-Plast. Technol. Eng. 2004, 43, 797-820.

18. Klemm, D.; Schumann, D.; Udhardt, U.; Marsch, S. Bacterial synthesized cellulose: Artificial blood vessels for microsurgery. Prog. Polym. Sci. 2001, 26, 1561-1603.

19. Hirai, A.; Tsuji, M.; Horii, F. TEM study of band-like cellulose assemblies produced by Acetobacter xylinum. Cellulose 2002, 9, 105-113.

20. Gindl, W.; Keckes, J. Tensile properties of cellulose acetate butyrate composites reinforced with bacterial cellulose. Composites Sci. Technol. 2004, 64, 2407-2413.

21. Guhados, G.; Wan, W.; Hutter, J.L. Measurement of the elastic modulus of single bacterial cellulose fibers using atomic force microscopy. Langmuir 2005, 21, 6642-6646.

22. Torres, F.G.; Troncoso, O.P.; Lopez, D.; Grande, C.; Gomez, C.M. Reversible stress softening and stress recovery of cellulose networks. Soft Matter 2009, 5, 4185-4190

23. Grande, C.J.; Torres, F.G.; Gomez, C.M.; Troncoso, O.P.; Canet-Ferrer, J.; Martínez-Pastor, J. Development of self-assembled bacterial cellulose-starch nanocomposites. Mater. Sci. Eng. C 2009, 29, 1098-1104.

24. Yamanaka, S.; Watanabe, K.; Kitamura, N.; Iguchi, M.; Mitsuhashi, S.; Nishi, Y.; Uryu, M. The structure and mechanical properties of sheets prepared from bacterial cellulose. J. Mater. Sci. 1989, 24, 3141-3145.

25. Yano, H.; Sugiyama, J.; Nakagaito, A.N.; Nogi, M.; Matsuura, T.; Hikita, M.; Handa, K. Optically transparent composites reinforced with networks of bacterial nanofibers. Adv. Mater. 2005, 17, 153-155. 
26. Touzel, J.-P.; Chabbert, B.; Monties, B.; Debeire, P.; Cathala, B. Synthesis and characterization of dehydrogenation polymers in gluconacetobacter xylinus cellulose and Cellulose/Pectin composite. J. Agric. Food Chem. 2003, 51, 981-986.

27. Mormino, R.; Bungay, H. Composites of bacterial cellulose and paper made with a rotating disk bioreactor. Appl. Microbiol. Biotechnol. 2003, 62, 503-506.

28. Petersen, N.; Gatenholm, P. Bacterial cellulose-based materials and medical devices: Current state and perspectives. Appl. Microbiol. Biotechnol.2011, 91, 1277-1286.

29. Bäckdahl, H.; Helenius, G.; Bodin, A.; Nannmark, U.; Johansson, B.R.; Risberg, B.; Gatenholm, P. Mechanical properties of bacterial cellulose and interactions with smooth muscle cells. Biomaterials 2006, 27, 2141-2149.

30. MacKintosh, F.C.; Käs, J.; Janmey, P.A. Elasticity of semiflexible biopolymer networks. Phys. Rev. Lett. 1995, 75, 4425-4428.

31. Chaudhuri, O.; Parekh, S.H.; Fletcher, D.A. Reversible stress softening of actin networks. Nature 2007, 445, 295-298.

32. Gatenholm, P.; Klemm, D. Bacterial nanocellulose as a renewable material for biomedical applications. MRS Bull. 2010, 35, 208-213.

33. Williams, D.F. The Williams Dictionary of Biomaterials; Liverpool University Press: Liverpool, UK, 1999.

34. Schumann, D.A.; Wippermann, J.; Klemm, D.O.; Kramer, F.; Koth, D.; Kosmehl, H.; Wahlers, T.; Salehi-Gelani, S. Artificial vascular implants from bacterial cellulose: preliminary results of small arterial substitutes. Cellulose 2009, 16, 877-885.

35. Hutmacher, D.W. Scaffold design and fabrication technologies for engineering tissues: State of the art and future perspectives. J. Biomater. Sci. Polym. Ed. 2001, 12, 107-124.

36. Svensson, A.; Nicklasson, E.; Harrah, T.; Panilaitis, B.; Kaplan, D.L.; Brittberg, M.; Gatenholm, P. Bacterial cellulose as a potential scaffold for tissue engineering of cartilage. Biomaterials $\mathbf{2 0 0 5}$, 26, 419-431.

37. Angelova, N. Rationalizing the design of polymeric biomaterials. Trends in Biotech. 1999, 17, 409-421.

38. Pértile, R.; Moreira, S.; Andrade, F.; Domingues, L.; Gama, M. Bacterial cellulose modified using recombinant proteins to improve neuronal and mesenchymal cell adhesion. Biotechnol Prog. 2012, 28, 526-532.

39. Pertile, R.A.N.; Andrade, F.K.; Alves, C.; Gama, M. Surface modification of bacterial cellulose by nitrogen-containing plasma for improved interaction with cells. Carbohyd. Polym. 2010, 82, 692-698.

40. Andrade, F.K.; Moreira, S.M.; Domingues, L.; Gama, F.M. Improving the affinity of fibroblasts for bacterial cellulose using carbohydrate-binding modules fused to RGD. J. Biomed. Mater. Res. A 2010, 92, 9-17.

41. Wang, J.; Wan, Y.Z.; Luo, H.L.; Gao, C.; Huang, Y. Immobilization of gelatin on bacterial cellulose nanofibers surface via crosslinking technique. Mater. Sci. Eng. C 2012, 32, 536-541.

42. Luo, H.; Xiong, G.; Huang, Y.; He, F.; Wang, Y.; Wan, Y. Preparation and characterization of a novel COL/BC composite for potential tissue engineering scaffolds. Mater. Chem. Phys. 2008, $110,193-196$. 
43. Cai, Z.; Yang, G. Bacterial cellulose/collagen composite: Characterization and first evaluation of cytocompatibility. J. Appl. Polym. Sci. 2011, 120, 2938-2944.

44. Kim, J.; Cai, Z.; Lee, H.S.; Choi, G.S.; Lee, D.H.; Jo, C. Preparation and characterization of a bacterial cellulose/Chitosan composite for potential biomedical application. J. Polym. Res. 2011, 18, 739-744.

45. Ul-Islam, M.; Shah, N.; Ha, J.H.; Park, J.K. Effect of chitosan penetration on physico-chemical and mechanical properties of bacterial cellulose. Korean J. Chem. Eng. 2011, 28, 1736-1743.

46. Cai, Z.; Chen, P.; Jin, H.J.; Kim, J. The effect of chitosan content on the crystallinity, thermal stability, and mechanical properties of bacterial cellulose: Chitosan composites. Proc. Inst. Mech. Eng. C J. Mech. E. 2009, 223, 2225-2230.

47. Wan, Y.Z.; Luo, H.; He, F.; Liang, H.; Huang, Y.; Li, X.L. Mechanical, moisture absorption, and biodegradation behaviours of bacterial cellulose fibre-reinforced starch biocomposites. Composites Sci. Technol. 2009, 69, 1212-1217.

48. Yin, N.; Chen, S.-y.; Ouyang, Y.; Tang, L.; Yang, J.-X.; Wang, H.-p. Biomimetic mineralization synthesis of hydroxyapatite bacterial cellulose nanocomposites. Prog. Nat. Sci. Mater. Int. 2011, $21,472-477$.

49. Wang, J.; Wan, Y.; Han, J.; Lei, X.; Yan, T.; Gao, C. Nanocomposite prepared by immobilising gelatin and hydroxyapatite on bacterial cellulose nanofibres. Micro Nano Lett. 2011, 6, 133-136.

50. Zimmermann, K.A.; LeBlanc, J.M.; Sheets, K.T.; Fox, R.W.; Gatenholm, P. Biomimetic design of a bacterial cellulose/hydroxyapatite nanocomposite for bone healing applications. Mater. Sci. Eng. C 2011, 31, 43-49.

51. Wan, Y.Z.; Gao, C.; Luo, H.L.; He, F.; Liang, H.; Li, X.L.; Wang, Y.L. Early growth of Nano-Sized calcium phosphate on phosphorylated bacterial cellulose nanofibers. J. Nanosci. Nanotechnol. 2009, 9, 6494-6500.

52. Wan, Y.; Hong, L.; Jia, S.; Huang, Y.; Zhu, Y.; Wang, Y.; Jiang, H. Synthesis and characterization of hydroxyapatite bacterial cellulose nanocomposites. Composites Sci. Technol. 2006, 66, 1825-1832.

53. Millon, L.E.; Oates, C.J.; Wan, W. Compression properties of polyvinyl alcohol bacterial cellulose nanocomposite. J. Biomed. Mater. Res. Part B 2009, 90, 922-929.

54. Millon, L.E.; Guhados, G.; Wan, W. Anisotropic polyvinyl alcohol Bacterial cellulose nanocomposite for biomedical applications. J. Biomed. Mater. Res. Part B 2008, 86, 444-452.

55. Millon, L.E.; Wan, W.K. The polyvinyl alcohol bacterial cellulose system as a new nanocomposite for biomedical applications. J. Biomed. Mater. Res. Part B 2006, 79, 245-253.

56. Olsson, R.T.; Kraemer, R.; LoÌpez-Rubio, A.; Torres-Giner, S.; Ocio, M.J.; LagaroÌn, J.M. Extraction of microfibrils from bacterial cellulose networks for electrospinning of anisotropic biohybrid fiber yarns. Macromolecules 2010, 43, 4201-4209.

57. Hagiwara, Y.; Putra, A.; Kakugo, A.; Furukawa, H.; Gong, J.P. Ligament-like tough double-network hydrogel based on bacterial cellulose. Cellulose 2010, 17, 93-101.

58. Bäckdahl, H.; Esguerra, M.; Delbro, D.; Risberg, B.; Gatenholm, P. Engineering microporosity in bacterial cellulose scaffolds. J. Tissue Eng. Regen. Med. 2008, 2, 320-330.

59. Ul-Islam, M.; Khan, T.; Park, J.K. Water holding and release properties of bacterial cellulose obtained by in situ and ex situ modification. Carbohyd. Polym. 2012, 88, 596-603. 
60. Kaewnopparat, S.; Sansernluk, K.; Faroongsarng, D. Behavior of freezable bound water in the bacterial cellulose produced by Acetobacter xylinum: An approach using thermoporosimetry. AAPS PharmSciTech 2008, 9, 701-707.

61. Dahman, Y. Nanostructured biomaterials and biocomposites from bacterial cellulose nanofibers. J. Nanosci. Nanotechnol. 2009, 9, 5105-5122.

62. Rambo, C.R.; Recouvreux, D.O.S.; Carminatti, C.A.; Pitlovanciv, A.K.; Antônio, R.V.; Porto, L.M. Template assisted synthesis of porous nanofibrous cellulose membranes for tissue engineering. Mater. Sci. Eng. C 2008, 28, 549-554.

63. Yoshikawa, H.; Myoui, A. Bone tissue engineering with porous hydroxyapatite ceramics. J. Artif. Organs 2005, 8, 131-136.

64. Stoica-Guzun, A.; Stroescu, M.; Jinga, S.; Jipa, I.; Dobre, T.; Dobre, L. Ultrasound influence upon calcium carbonate precipitation on bacterial cellulose membranes. Ultrason. Sonochemistry 2012, 19, 909-915.

65. Gao, C.; Xiong, G.Y.; Luo, H.L.; Ren, K.J.; Huang, Y.; Wan, Y.Z. Dynamic interaction between the growing $\mathrm{CaP}$ minerals and bacterial cellulose nanofibers during early biomineralization process. Cellulose 2010, 17, 365-373.

66. Zhang, S.; Xiong, G.; He, F.; Huang, Y.; Wang, Y.; Wan, Y. Characterisation of hydroxyapatite/bacterial cellulose nanocomposites. Polym. Polym. Composites 2009, 17, 353-358.

67. Hamilton, D.; Vorp, D. Tissue Engineering of Blood Vessel, 2nd Edition; Informa HealthCare: London, UK, 2008.

68. Czaja, W.K.; Young, D.J.; Kawecki, M.; Brown, R.M. The future prospects of microbial cellulose in biomedical applications. Biomacromolecules 2006, 8, 1-12.

69. Brown, E.E.; Laborie, M.-P.G.; Zhang, J. Glutaraldehyde treatment of bacterial cellulose/fibrin composites: Impact on morphology, tensile and viscoelastic properties. Cellulose 2012, 19, 127-137.

70. Mohammadi, H. Nanocomposite biomaterial mimicking aortic heart valve leaflet mechanical behaviour. Proc. Inst. Mech. Eng. H 2011, 225, 718-722.

71. Fink, H.; Faxalv, L.; Molnár, G.F.; Drotz, K.; Risberg, B.; Lindahl, T.L.; Sellborn, A. Real-time measurements of coagulation on bacterial cellulose and conventional vascular graft materials. Acta Biomater. 2010, 6, 1125-1130.

72. Andrade, F.K.; Silva, J.P.; Carvalho, M.; Castanheira, E.M.S.; Soares, R.; Gama, M. Studies on the hemocompatibility of bacterial cellulose. J. Biomed. Mater. Res. Part A 2011, 98, 554-566.

73. Farah, L.F.X. Process for the Preparation of Cellulose Film, Cellulose Film Produced thereby, Artificial Skin Graft and its Use. U.S. Patent 4,912,049, 27 March 1990.

74. Fontana, J.D.; Souza, A.M.; Fontana, C.K.; Torriani, I.L.; Moreschi, J.C.; Gallotti, B.J.; Souza, S.J.; Narcisco, G.P.; Bichara, J.A.; Farah, L.F.X. Acetobacter cellulose pellicle as a temporary skin substitute. Appl. Biochem. Biotech. 1990, 24-25, 253-264.

75. Legeza, V.I.; Galenko-Yaroshevskii, V.P.; Zinov'ev, E.V.; Paramonov, B.A.; Kreichman, G.S.; Turkovskii, I.I.; Gumenyuk, E.S.; Karnovich, A.G.; Khripunov, A.K. Effects of new wound dressings on healing of thermal burns of the skin in acute radiation disease. Bull. Exp. Biol. Med. 2004, 138, 311-315. 
76. Azuma, C.; Yasuda, K.; Tanabe, Y.; Taniguro, H.; Kanaya, F.; Nakayama, A.; Chen, Y.M.; Gong, J.P.; Osada, Y. Biodegradation of high-toughness double network hydrogels as potential materials for artificial cartilage. J. Biomed. Mater. Res. Part A 2007, 81, 373-380.

77. Levinson, D.J.; Glonek, T. Microbial Cellulose Contact Lens. U.S. Patent 7,832,857, 16 November 2010.

78. Shi, Z.; Zang, S.; Jiang, F.; Huang, L.; Lu, D.; Ma, Y.; Yang, G. In situ nano-assembly of bacterial cellulose-polyaniline composites. RSC Adv. 2012, 2, 1040-1046.

79. Trovatti, E.; Silva, N.H.C.S.; Duarte, I.F.; Rosado, C.F.; Almeida, I.F.; Costa, P.; Freire, C.S.R.; Silvestre, A.J.D.; Neto, C.P. Biocellulose membranes as supports for dermal release of lidocaine. Biomacromolecules 2011, 12, 4162-4168.

80. Park, H.O.; Bang, Y.B.; Joung, H.J.; Kim, B.C.; Kim, H.R. Lactobacillus KCTC 0774BP and Acetobacter KCTC 0773BP for Treatment or Prevention of Obesity and Diabetes Mellitus. U.S. Patent 6,808,703, 26 October 2004.

(C) 2012 by the authors; licensee MDPI, Basel, Switzerland. This article is an open access article distributed under the terms and conditions of the Creative Commons Attribution license (http://creativecommons.org/licenses/by/3.0/). 